\title{
Cenário histórico das relações públicas no Brasil
}

\section{The historical scenario of public relations in Brazil}

\section{Escenario histórico de las relaciones públicas en Brasil}

\section{Paulo Nassar}

- Pós-doutor pela Libera Università di Lingue e Comunicazione, Milão, Itália

- Doutor e mestre em Ciências da Comunicação, na área de Relações Públicas, pela Escola de Comunicações e Artes da Universidade de São Paulo (ECA-USP)

- Professor livre-docente da ECA-USP

- Coordenador do Grupo de Estudos de Novas Narrativas (Genn/ECA-USP)

- $\quad$ Diretor-presidente da Associação Brasileira de Comunicação Empresarial (Aberje)

- E-mail: paulonassar@usp.br

\section{Luiz Alberto de Farias}

- Pós-doutor pela Universidad de Málaga, Espanha

- Doutor em Comunicação e Cultura pela Universidade de São Paulo (USP)

- Mestre em Comunicação e Mercado pela Faculdade Cásper Líbero (Facásper)

- Professor da Pós-Graduação em Ciências da Comunicação da ECA-USP

- Diretor acadêmico das escolas de Comunicação e de Educação da Universidade Anhembi-Morumbi

- Presidente da Associação Brasileira de Pesquisadores de Comunicação Organizacional e de Relações Públicas (Abrapcorp)

- E-mail: lafarias@usp.br

\section{Mateus Furlanetto de Oliveira}

- Mestre em Ciências da Comunicação pela ECA-USP

- Especialista em Gestão Estratégica de Comunicação Organizacional e Relações Públicas pela ECA-USP

- Graduado em Relações Públicas pela ECA-USP

- $\quad$ Foi gerente de Relações Públicas da Associação Brasileira de Comunicação Empresarial (Aberje)

- Professor da Faculdade Cásper Líbero (Facásper)

- E-mail:mateusfur@uol.com.br 


\section{Resumo}

As relações públicas surgiram no Brasil em 1914, com a criação do primeiro departamento corporativo de da área, em São Paulo. No entanto, seu desenvolvimento ocorreu apenas a partir de 1950. Ao se estabelecerem no Brasil, as empresas multinacionais criaram departamentos de relações públicas para melhorar e fortalecer suas atividades no país. Um aspecto singular, no Brasil, é que a profissão foi regulamentada em 1967, pela Lei n⿳05377/67. No mesmo ano, foi criado o primeiro curso de graduação, na Universidade de São Paulo. Inspirados pelas teorias norte-americanas, europeias e latino-americanas, vários autores têm escrito livros conceituais e práticos para o mercado brasileiro, contribuindo para o desenvolvimento da profissão. Diversas associações também desempenharam papel crucial nesse sentido, construindo pontes entre o meio acadêmico e 0 mercado. Este texto apresenta fatos relevantes dos cem anos de relações públicas no Brasil, comemorados em 2014.

\section{PALAVRAS-CHAVE: BRASIL・LICENCIAMENTO・COMUNICACC̃̃O ORGANIZACIONAL・RELACC̃̃ES PÚBLICAS・HISTÓRIA}

\section{Abstract}

Public relations arose in Brazil in 1914, with the creation of the first corporate department of the area, in São Paulo. However, it development only occurred as from 1950. When establishing themselves in Brazil, the internactional companies created public relations departments to improve and strengthen their activities in the country. A unique aspect in Brazil is that the profession was regulated in 1967, by Law No. 5.377/67. In the same year the first graduate course was created in the University of São Paulo. Inspired by the North American, European and Latin American theories, a number of authors have written conceptual and practical books for the Brazilian market, contributing to the development of the profession. Various associations have also played a crucial role in this sense, by building bridges between the academic environment and the market. This text presents relevant facts of the one hundred years of public relations in Brazil, celebrated in 2014.

\section{KEYWORDS: BRAZIL・LICENSING・ORGANIZATIONAL COMMUNICATION・PUBLIC RELATIONS・HISTORY.}

\section{Resumen}

Las relaciones públicas surgieron en Brasil en 1914, con la creación del primer departamento corporativo del área, en São Paulo. Pero, su desenvolvimiento ocurrió apenas a partir de 1950.. Al establecerse en el Brasil, las organizaciones multinacionales crearon departamentos de relaciones públicas para mejorar y fortalecer sus actividades en el país. Un aspecto singular en Brasil, es que la profesión fue reglamentada en 1967, por la Ley n0 5377/67. En el mismo año, fue creado el primeo curso de graduación, en la Universidad de São Paulo. Inspirados por las teorías norteamericanas, europeas y latinoamericanas, varios autores han escrito libros conceptuales y prácticos para el mercado brasilero, contribuyendo para el desarrollo de la profesión. Diversas asociaciones también desempeñaron un papel crucial en este sentido, construyendo puentes entre el medio académico y el mercado. Este texto presenta hechos relevantes de los cien años de las relaciones públicas en el Brasil, conmemorados en 2014. 
A s origens das relações públicas no Brasil remontam ao início do século XX (M. Kunsch, 1997; W. Kunsch, 2009). Mais 1 precisamente, o marco fundador pode ser definido como o dia 30 de janeiro de 1914, quando foi criado o Departamento de Relações Públicas da empresa canadense The São Paulo Tramway, Light and Power Company Limited, atual AES Eletropaulo, tendo como seu primeiro engenheiro Eduardo Pinheiro Lobo, sob o comando do canadense Alexander Mackenzie, um personagem a ser mais bem estudado pelas relações públicas brasileiras, em suas verificações de origem, principalmente de sua paternidade (Nassar, Furlanetto e Flynn, 2015; Nassar, 2015). Outra iniciativa importante ocorreu em 1926, quando a General Motors, recém-chegada ao Brasil, começou a publicar o boletim mensal do empregado, o General Motors, a primeira revista industrial publicada no Brasil (Torquato, 1987). Isso ilustra que "desde o início do século XX, entre as décadas de 1910 a 1940, a prática de atividades de relações públicas estava restrita a poucas corporações internacionais e a alguns setores de informação pública em departamentos governamentais e instituições (Fernandes, 2011 p. 39).

A primeira empresa brasileira a criar um departamento de Relações Públicas foi a Companhia Siderúrgica Nacional (CSN), em 1951 (M. Kunsch, 1997), com o objetivo de promover a indústria siderúrgica e sua importância simbólica para a nação. Essa empresa surgiu por iniciativa do então presidente do país, Getúlio Vargas (1882-1954), como resultado do chamado Acordo de Washington, assinado pelos governos do Brasil e dos Estados Unidos. Essa iniciativa político-militar incluía a construção de uma usina de laminação de aço que forneceria a matéria para os aliados durante a Segunda Guerra Mundial e simbolizaria o desenvolvimento e o crescimento do Brasil.

O caso da Companhia Siderúrgica Nacional mostra que as atividades de relações públicas, no Brasil, tiveram início efetivamente na década de 1950, graçasà combinação de vários fatores. Umera que a democracia havia estimulado uma política de desenvolvimento industrial, à qual se seguiu a abertura e o crescimento do mercado interno. Grandes multinacionais estrangeiras vieram para 0 Brasil, criaram departamentos de Relações Públicas, replicando a estrutura e características de setores congêneres de suas matrizes (M. Kunsch; Nassar, 2009, p. 655). Esse ambiente ajudou a reforçar e valorizar a atividade no Brasil. Além disso, naquele momento também se formavam os grandes conglomerados de jornais, revistas e rádio, se faziam as primeiras transmissões de televisão no país. Em tal cenário, as relações públicas estabeleceram sua posição como uma atividade empresarial.

Em resposta às demandas que surgiam, em 1953 foi ministrado o primeiro curso de formação, organizado pelas instituições Fundação Getúlio Vargas, Instituto de Administração da Universidade de São Paulo, Instituto de Organização Racional do Trabalho (Idort) e Organização das Nações Unidas. Ele foi conduzido pelo professor norte-americano Eric Carlson. Mais tarde, em 1955, o professor Harwood Childs, da Universidade de Princeton, apresentou em São Paulo um curso para introduzir a teoria contemporânea das relações públicas. Iniciativas para a profissionalização e organização da área foram simbolizadas pela criação da Associação Brasileira de Relações Públicas (ABRP) por líderes profissionais, em 1954 (W. Kunsch, 2009).

Quatro anos depois, em 1958, foi realizado o I Seminário Brasileiro de Relações Públicas, como uma plataforma para a consolidação da atividade no Brasil. Os trabalhos apresentados no seminário são indicativos dos imperativos do tempo: "Normas e padrões para o trabalho de relações públicas", por Ney Peixoto do Valle; "As comunicações das relações públicas", por João Firminiano da Silva; e "Treinamento e formação de pessoal para relações públicas", por Francisco Gomes de Matos e Cel. Terêncio M. Porto. Esse evento mostrou que o ambiente era propício para o desenvolvimento da atividade no Brasil.

Nos anos seguintes, uma série de outros eventos foi levada a efeito em todo o país, como o I Congresso Paranaense de Relações Públicas (Curitiba, 1959) e o I Congresso Mineiro de Relações Públicas (Belo Horizonte, 1962). Também digna de nota foi a IV Conferência Interamericana de Relações Públicas, em 1963, realizada no Rio de Janeiro, organizada pela ABRP. Os delegados vieram de Uruguai, Argentina, Chile, Paraguai, Peru, Equador, Colômbia, Venezuela, Antilhas Holandesas, México, Porto Rico 
e Estados Unidos (Fernandes, 2011). O IV Congresso Internacional de Relações Públicas, da International Public Relations Association (Ipra), teve lugar no Rio de Janeiro, em outubro de 1967 (M. Kunsch, 1997). As principais iniciativas empreendedoras também alavancaram a profissão de relações públicas, notadamente a criação da $A A B$, a primeira consultoria brasileira da área, em 1962. Até então, o trabalho era realizado por agências de publicidade.

O primeiro livro sobre relações públicas, no Brasil e na América Latina, foi Para entender relações públicas, de Cândido Teobaldo de Souza Andrade, em 1962 (W. Kunsch, 2009). Com isso, Andrade foi o primeiro autor brasileiro na área, sendo ele considerado por muitos como o verdadeiro pioneiro e "pai" das relações públicas no Brasil. Escreveu sete livros sobre teorias e práticas, tendo sido dele a primeira tese de doutorado da área no Brasil, Relações públicas e o interesse público, defendida na Escola de Comunicações e Artes da Universidade de São Paulo (ECA-USP), em 1973. E ainda foi, em 1967, um dos professores fundadores do programa de bacharelado de Relações Públicas da então Escola de Comunicações Culturais (ECC), nome inicial da Escola de Comunicações e Artes.

\section{REGULAMENTAÇÃO DA PROFISSÃO}

Em 1964, o Brasil passou a ser governado pelos militares, após um golpe de Estado, instaurando-se uma ditadura que perdurou por 21 anos. A profissão de relações públicas foi regulamentada nesse interim, através da Lei $n^{0}$ 5.377, de 11 de dezembro de 1967, e legalizada pelo Decreto-Lei n⿳⺈ 63.283, de 26 de setembro de 1968. A lei restringia o exercício da atividade a graduados em Comunicação Social com habilitação em Relações Públicas.

0 Brasil foi o primeiro país do mundo a regulamentar a profissão de relações públicas. No entanto, o licenciamento da profissão era prematuro, porque naquela época as atividades de relações públicas não foram reconhecidas nem pela academia, nem pela sociedade, apesar dos esforços feitos nesse sentido, por exemplo, pela ABRP (M. Kunsch, 1997 p. 22).

Embora tenha sido uma profissão regulamentada desde 1967, a licença não garante o exercício da profissão apenas aos profissionais registrados. A legalização da profissão pelo governo militar foi em grande parte para restringir e controlar o direito à liberdade de expressão e das relações sociais, principalmente na área da comunicação social. Atualmente, as empresas brasileiras contratam profissionais de várias formações acadêmicas, como, por exemplo, jornalismo, publicidade, marketing, administração, direito, ciências sociais, além de relações-públicas, para gerenciar seus departamentos de comunicação corporativa. Esta área ou departamento dentro de uma empresa raramente é chamado de Relações Públicas; são adotados nomes como comunicação corporativa, comunicação institucional, comunicação empresarial ou apenas comunicação. Em 1971 , foram criados o Conselho Federal de Profissionais de Relações Públicas (Conferp) e os Conselhos Regionais de Profissionais de Relações Públicas (Conrerp's), com o objetivo de emitir o registro profissional e supervisionar as atividades de relações públicas no Brasil. Atualmente o Conrerp opera através de um sistema de sete conselhos regionais (Conrerp's).

M. Kunsch e Nassar (2009, p. 655) consideram que "o ano de 1967 foi um marco para as relações públicas no Brasil e para a relação entre a academia e as organizações empresariais". Já foi dito antes que nesse ano se criou o primeiro curso de graduação em Relações Públicas, na então Escola de Comunicações Culturais da Universidade de São Paulo. No mesmo ano, nascia a Associação Brasileira de Editores de Revistas e Jornais de Empresas (Aberje), por iniciativa do jornalista Nilo Luchetti, gerente de relações públicas da Pirelli. Anos depois, a Aberje, mantendo esse acrônimo, passaria a chamar-se de Associação Brasileira de Comunicação Empresarial. As grandes corporações nacionais e multinacionais que possuíam departamentos de comunicação e relações públicas associaram-se à Aberje, beneficiando-se de sua variada oferta de programas educacionais, 
pesquisas, conferências, reuniões, publicações (Caldas Junior, 2005). Luchetti também criou o Prêmio Aberje, que desde então distingue, anualmente, trabalhos de excelência na área da comunicação empresarial.

Na década de 1970, planejamento de eventos, cerimonial, redação de discursos, entre outras, foram as principais atividades de relações públicas praticadas nas instituições e nos órgãos governamentais. 0 mesmo tipo de atividades teve lugar nas corporações. Nesta década foi estabelecida [uma série de novas agências de relações públicas" (Fernandes, 2011, p. 44).

Na área acadêmica, a primeira tese de doutorado em Jornalismo Empresarial foi defendida por Francisco Gaudêncio Torquato do Rego, na ECA-USP, em 1973. Uma década depois, em 1983, ele apresentou sua tese de livre-docência na mesma instituição, preconizando a necessidade de utilizar a comunicação empresarial de uma forma sinérgica, a fim de obter resultados eficazes dentro das organizações.

As técnicas de relações públicas foram amplamente utilizadas pelos governantes militares que mantiveram o poder no Brasil de 1964 a 1985. Em 1968, foi criada a Assessoria Especial de Relações Públicas (Aerp). Durante o governo do general Médici (19691974), a Aerp constituiu-se em verdadeiro escritório político de propaganda para 'promover' o regime ditatorial, mascarando, assim, a intervenção de censura mais violenta na história do Brasil (M. Kunsch, 1997, p. 26). Torquato (2002, p. 3) criticou fortemente a abordagem da ditadura: a máquina de relações públicas bem equipada, usada pelos governantes militares como um centro de propaganda e comunicação vangloriosa, se caracterizou pela linguagem grandiloquente da comunicação empresarial no início de 1970 e foi bem respeitada pelos veículos da grande mídia, a maioria dos quais foi submetida à censura prévia.

Durante o governo do general Ernesto Geisel (1974-1979), a Aerp, que tinha operado na primeira metade da década na promoção de ações governamentais, encerrou suas operações e foi fechada. Em 1975 foi substituída pela Assessoria de Imprensa e Relações Públicas (AIRP), que, mais tarde, se dividiu em duas, dando origem à Assessoria de Relações Públicas (ARP). A imagem dos profissionais de relações públicas foi manchada pelas ações empreendidas pela ARP, onde atuavam como spin doctors, tentando mudar a narrativa de fatos como a prisão e a tortura de milhares de brasileiros que exigiam o retorno da democracia. Um exemplo disso foi o assassinato do jornalista Vladimir Herzog em uma prisão militar de São Paulo, em outubro de 1975, que causou grande comoção e foi documentado por numerosas instituições nacionais e internacionais. A versão oficial do evento, que foi lançada ao público através da ARP na época, era que o jornalista havia cometido suicídio quando, na verdade, ele foi torturado e morto pelos militares (Nassar, 2012).

Na década de 1980, quatro fatores contribuíram para o fortalecimento das atividades de relações públicas no Brasil: a transformação econômica, a abertura política, o estabelecimento da democracia e o desenvolvimento de pesquisas científicas (Fernandes, 2011, p. 44). Este ambiente social, político e cultural estimulou mudanças significativas nos comportamentos organizacionais, no governo e na iniciativa privada, transformando o modo de condução da comunicação empresarial. Com a redução do autoritarismo após anos de regime militar, a sociedade brasileira começou a exigir mais transparência dos governos e das empresas. 0 antigo estilo de gestão não atendia mais a seu propósito e as circunstâncias clamavam por mudanças radicais também na comunicação empresarial.

Os primeiros sindicatos de profissionais de relações públicas foram estabelecidos no Rio Grande do Sul (1981), no Rio de Janeiro (1984) e em São Paulo (1985). Naquela década, várias associações também floresceram: a Associação Brasileira de Empresas de Relações Públicas (Aberp), em 1983; a Associação Nacional de Empresas de Comunicação Empresarial (Anece), em 1985; e 0 Sindicato Nacional das Empresas de Comunicação (Sinco), em 1989. Com o crescimento das agências de comunicação e relações públicas nos anos 1990, não fazia sentido ter duas associações que representassem as agências. Então a Aberp e a Anece se 
fundiram em 1999, formando a Associação Brasileira de Empresas de Comunicação (Abec), que acabou sendo dissolvida em 2001. Em 2002 foi criada a Associação Brasileira das Agências de Comunicação (Abracom) (Fernandes, 2011, p. 46).

\section{RELAÇÕES PÚBLICAS CONTEMPORÂNEAS}

Ao longo da década de 1980 foram feitas as primeiras tentativas para alcançar uma comunicação empresarial estratégica e integrada no Brasil. A primeira empresa a operar dentro desse novo âmbito institucional foi a francesa Rhodia SA, que em janeiro de 1985 lançou sua política de comunicação social. Intitulada Portas abertas, essa política logo se tornou referência para outras empresas que procuravam estabelecer canais de comunicação abertos com seus públicos de relacionamento. Durante o mesmo período, Margarida Kunsch defendia sua dissertação de mestrado, que daria origem ao livro Planejamento de relações públicas na comunicação integrada (1986) - e, mais tarde, com seu doutorado, ao livro Planejamento de relações públicas na comunicação integrada (1997). Essas obras se tornaram referências para a prática da área no país, já que oferecem uma abordagem passo a passo e preconizam a prática das relações públicas a partir de uma perspectiva da comunicação integrada. É nesse contexto que entra Gaudêncio Torquato, já mencionado. Ele e Margarida podem ser considerados os pioneiros da comunicação integrada no Brasil.

Outra contribuição importante para a teoria brasileira das relações públicas foi, em 1984, o livro Relações públicas: função política, de Roberto Porto Simões, que aplicou uma perspectiva crítica à teoria, aos currículos acadêmicos, ao perfil profissional, à prática, à ética e à estética desse campo. A partir dessa década de 1980 houve um aumento na produção e publicação de livros, dissertações de mestrado e teses de doutorado com foco em relações públicas.

Em 1989, a Aberje mudou seu nome para Associação Brasileira de Comunicação Empresarial, mantendo sua sigla, hoje conhecida como uma marca.

O novo nome foi uma tentativa de expressar a transformação em curso na comunicação empresarial e em nosso relacionamento com empresas, que estavam tomando seus primeiros passos em direção a uma grande reestruturação em um país que foi mais uma vez respirar o ar da democracia (Nassar, 2009, p. 30).

Desde a sua fundação, a Aberje tem contribuído para o fortalecimento das relações públicas e da comunicação empresarial através do compartilhamento de conhecimento, programas de educação, cursos, conferências, seminários, publicações, reuniões e pesquisa.

A Aberje tem como objetivo ser uma fonte de referência para a produção e difusão de conhecimentos sobre práticas de comunicação que orientam as estratégias de gestão dentro das organizações (...), a fim de reforçar o papel estratégico das comunicações no mundo dos negócios (M. Kunsch; Nassar, 2009, p. 658).

A entidade desempenhou um papel importante para reforçar e aperfeiçoar a atividade de relações públicas nos campos profissional e educacional, oferecendo a base para a prática das modernas relações públicas no Brasil. Como exemplo, ela lançou, em 1991, Comunicação Empresarial, a primeira revista brasileira voltada para a comunicação corporativa e as relações públicas, com circulação ininterrupta até hoje, sendo a segunda mídia especializada mais lida pelos executivos de comunicação no país.

Na década de 1990, o Sistema Conferp organizou um amplo debate sobre a profissão, com seu Parlamento Nacional de Relações Públicas (1997), destinado a rever alguns aspectos da lei de regulamentação da profissão, especialmente os requisitos para 
o registro profissional. Após cinco anos de discussão (1992-1997), o documento final foi apresentado ao mercado durante 0 Congresso Brasileiro de Relações Públicas realizado na cidade de Salvador (BA). As principais decisões foram: a) manutenção da exigência de registro profissional para exercer a profissão; e b) aceitar registro profissional de praticantes que tivessem outra formação que não a de relações públicas, tais como administração de empresas, jornalismo, publicidade e outros cursos de graduação, mas que tivessem uma pós-graduação específica em relações públicas (Athaydes et al., 2014, p. 156).

Em 2002, foi criada a Associação Brasileira de Agências de Comunicação (Abracom), para representar as agências que prestam serviços ligados à gestão de relações estratégicas de comunicação. Ela se propõe embasar as normas operacionais e profissionais para o segmento de comunicação corporativa e de negócios no seu relacionamento com clientes, fornecedores, entidades representativas, governo e comunidades locais. Ela também tem como objetivo fortalecer a participação de agências de comunicação no mercado privado e expandir sua presença no setor público (Abracom, 2012).

No campo científico, uma importante contribuição foi o surgimento da Associação Brasileira de Pesquisadores de Comunicação Organizacional e Relações Públicas (Abrapcorp), em 2006. Sob a liderança de Margarida M. Krohling Kunsch, a entidade foi criada por um grupo de pesquisadores brasileiros que atuam em universidades e no ambiente de comunicação corporativa. Desde o começo, a Abrapcorp vem realizando seminários científicos anuais com a presença de estudiosos de destaque na investigação e no desenvolvimento de trabalhos relacionados com a comunicação organizacional e as relações públicas, publicando seus resultados em obras lançadas anualmente.

Além de Cândido Teobaldo de Souza Andrade, Margarida K. Kunsch, Roberto Porto Simões e Gaudêncio Torquato, podemos citar, entre muitos outros, os seguintes autores que que exerceram influência sobre pesquisadores e profissionais: Roberto de Castro Neves - Imagem empresarial (1998); Waldyr Gutierrez Fortes - Relações públicas: processo, funções, tecnologia e estratégias (2003); Carlos Eduardo Mestieri - Relações públicas: arte de harmonizar expectativas (2006); Paulo Nassar - Relações públicas na construção da responsabilidade histórica e no resgate da memória institucional das organizações (2007); Lalá Aranha - Cartas a uma jovem relações-públicas (2010); Luiz Alberto de Farias (organizador) - Relações Públicas estratégicas: técnicas, conceitos e instrumentos (2011); Fabio França - Públicos: como identificá-los em nova visão estratégica (2012); Marlene Marchiori - Coleção "Faces da cultura e da comunicação" (2014 - dez volumes).

Em 2010, foi convocado pelo Ministério da Educação um comitê de especialistas, para formular a Proposta de Diretrizes Curriculares Nacionais para os cursos de Relações Públicas. A comissão trabalhou de maio a outubro desse ano, focada nos seguintes temas: a) perfil desejado do profissional de relações públicas em face das mudanças política, cultural, social e tecnológica contemporâneas; b) habilidades profissionais a serem ensinadas no ensino superior em termos de conhecimentos, técnicas, atitudes e valores; e c) instrumentos de aprendizagem e mecanismos utilizados pela academia para ensinar seus alunos. A nova proposta foi aprovada em 2013, devendo todos os cursos de graduação em Relações Públicas seguir as novas diretrizes (Brasil, 2010).

\section{AMBIENTE PROFISSIONAL}

Deacordo com pesquisa realizada pelo DatAberje, instituto de pesquisa da Aberje (2008,2010,2012b, 2013), na última década, as principais responsabilidades dos profissionais de comunicação empresarial estavam ligadas a comunicação interna, relações institucionais, relações governamentais/relações públicas, assessoria de imprensa, responsabilidade social corporativa, 
gerenciamento de crise, sustentabilidade, relações com investidores, memória empresarial e branding. 0 comunicador se tornou um mediador, um gestor de equipe e dos relacionamentos organizacionais. Atualmente, as organizações são um ponto em uma enorme rede e devem construir a sua imagem e reputação por meio do diálogo com seus múltiplos públicos.

Os dados revelam o crescimento da área de comunicação organizacional. Desde 0 ano 2000, os investimentos na área têm crescido, reafirmando o prestígio e poder das atividades e do profissional dentro das corporações. No entanto, em apenas metade das empresas pesquisadas (Aberje, 2013), o principal gestor da comunicação integra o comitê executivo ou o conselho. Em tamanho, a maioria dos departamentos de relações públicas e comunicação varia de quatro a dez profissionais, sendo esse número maior em grandes corporações. Apesar de enxutas, essas áreas são responsáveis por importantes atividades no cotidiano do negócio, como a gestão estratégica dos relacionamentos com os colaboradores, a comunidade, o governo, a imprensa e a sociedade civil organizada.

Outro estudo, realizado pela Aberje/DMR Consulting, com foco em fornecedores de comunicação corporativa, revelou que $75 \%$ das corporações contratam fornecedores externos para a assessoria de imprensa, 70\% para eventos, $62 \%$ para a comunicação interna, 53\% para pesquisa e mensuração, 40\% para gestão de marca, 20\% para memória empresarial, 19\% para a responsabilidade social corporativa/sustentabilidade, 13\% para o patrocínio, 10\% para relações com investidores e 9\% para relações governamentais (Aberje, 2012b). A criatividade dos profissionais locais, associada ao perfil receptivo do brasileiro, produz uma situação favorável para a implementação de modelos colaborativos de comunicação e aumenta a receptividade em relação a iniciativas na área.

\section{CONSIDERAÇÕES FINAIS}

O Brasil foi o primeiro e é um dos poucos países no mundo onde a profissão de relações públicas é regulamentada por lei. Isso, entretanto, não garantiu mais oportunidades de emprego para os profissionais, nem contribuiu para melhorar a imagem da atividade. Pelo contrário, esta foi enfraquecida pelo uso dela feito durante a ditadura militar no país.

São poucos os casos onde se encontram profissionais contratados para uma função que tenha o nome de relações-públicas, nas organizações privadas; a maioria dos postos tem o título de gestor de comunicação. Como mostrado na pesquisa Comunicação corporativa nas organizações (Aberje, 2008), os líderes de departamentos de comunicação em organizações brasileiras vêm de várias formações acadêmicas, tais como: jornalismo (29\%), administração (20\%), marketing (17\%), publicidade (13\%) e relações públicas (12\%). Os princípios, a filosofia e as técnicas de relações públicas são valorizados e utilizados pelas organizações, mas, na maioria das vezes, estão sob o nome de comunicação corporativa.

Para entender melhor o papel da atividade de relações públicas no Brasil de hoje, é preciso levar em conta as novas configurações sociais, políticas, econômicas, culturais e tecnológicas do país. Foram iniciados debates promovidos pelo Conselho Federal de Profissionais de Relações Públicas (Conferp) com os representantes das principais associações da área (Aberje, ABRP, Abracom e Abrapcorp), no que se refere à revisão da Lei n-5377, para atualizar e refletir o atual contexto profissional da área. Os resultados das discussões indicam um chamado para que a área seja mais aberta a profissionais com formação nas demais disciplinas da comunicação, como jornalismo, publicidade e marketing, além de não se limitar apenas a graduados em comunicação social.

Com o processo de ampliação da presença de empresas brasileiras com atuação internacional e global, apresenta-se um novo desafio para os profissionais da comunicação empresarial e das relações públicas, que é a definição de políticas globais 
de comunicação do Brasil para suas operações no mundo todo. Departamentos de comunicação corporativa, no Brasil, estão ampliando seu alcance em relação à responsabilidade social corporativa e sustentabilidade, às relações públicas em um ambiente não regulamentado, às mídias digitais e ao engajamento das partes interessadas. Instituições de ensino e associações industriais estão cientes desses desafios e dispostas a ajudar os profissionais de comunicação a melhorarem seus conhecimentos e suas habilidades para construir um forte relacionamento com os stakeholders.

Em síntese, os quatro temas-chave que diferenciam a profissão e a prática das atividades de relações públicas no Brasil se referem ao impacto da regulamentação do exercício da profissão; ao impacto negativo e à percepção dos profissionais de relações públicas durante a ditadura militar; ao crescimento e desenvolvimento da pesquisa acadêmica e do desenvolvimento profissional nas universidades e associações profissionais; e, finalmente, ao impacto da globalização nas empresas brasileiras e à necessidade de ser mais transparente e comunicativo em âmbito internacional ligado aos negócios.

Ao longo dos últimos cemanos da atividade de relações públicas no Brasil, a profissão passou de uma simplesárea responsável pela redação de press releases e publicações internas das empresas, tornando-se responsável pelo estabelecimento e pela difusão dos valores organizacionais, posicionando as organizações de forma aberta e transparente no ambiente global.

\section{REFERÊNCIAS}

ABERJE. Comunicação corporativa nas organizações. São Paulo: Aberje, 2008. Disponível em: <http://issuu.com/aberje/docs/ comunica_o_corporativa_nas_ organiza__es?mode=embed\&documentld=090213145019-1be6f2e452fe4527a7cb52950 ac5caad\&layout=grey>. Acesso em: 20 maio 2012.

Estudo de remuneração em comunicação organizacional. São Paulo: Aberje e DMR Consulting, 2010.

Uma associação profissional e científica. Aberje, 2012a. Disponível em: <http://www.aberje.com.br/>. Acesso em: 22 maio 2012.

Estudo sobre o mercado de forncedores de comunicação. São Paulo: Aberje e DMR Consulting, 2012b.

Perfil do profissional de comunicação corporativa no Brasil. São Paulo: Aberje e DMR Consulting, 2013.

ABRACOM. Associação Brasileira das Agências de Comunicação. Quem somos. 2012. Disponível em: <http://www1.abracom. org.br/cms/opencms/abracom/pt/quemsomos/>. Acesso em: 20 maio 2012.

ANDRADE, Candido Teobaldo de Souza. Para entender relações públicas. São Paulo: Loyola, 1962.

ATHAYDES, Andréia et al. Transcultural study on leadership in public relations and communications management: results for Brazil. In: BERGER, Bruce K.; MENG, Juan (org.). Public relations leaders as sensemakers: a global study of leadership in public relations and communication management. Nova York; Londres: Routledge, 2014. p. 247-261.

BRASIL. Ministério da Educação. Proposta de diretrizes curriculares parágrafo os cursos de Relações Públicas. Relatório da comissão de especialistas instituída pelo Ministério da Educação. Portaria 595/2010, de 24 de maio de 2010. Brasília: 20 out. 2010. Disponível em: <http://www. abrapcorp.org.br/diretrizes/Diretrizes_Curriculares_RP.pdf>. Acesso em: 25 maio 2012. 
CALDAS JÚNIOR, L. M. R In bocca al lupo! [Boa sorte]. Comunicação Empresarial, São Paulo, n. 54, p. 4-6, 1. trim. 2005.

FERNANDES, Backer Ribeiro. História das relações públicas: surgimento e consolidação na América do Sul. In: FARIAS, Luiz Alberto (org.). Relações públicas estratégicas: técnicas, conceitos e instrumentos. São Paulo: Summus. 2011. p. 21-49.

KUNSCH, Margarida M. Krohling. Relações públicas e modernidade: novos paradigmas na comunicação organizacional. São Paulo: Summus, 1997.

. Planejamento de relações públicas na comunicação integrada. [1986]. 4. ed. São Paulo: Summus, 2003.

KUNSCH, Margarida M. Krohling; NASSAR, Paulo. The relationship between the academy and professional organizations in the development of organizational communication. Management Communication Quarterly, v. 22, p. 655-662, 2009.

KUNSCH, Waldemar Luiz. Gênese e desenvolvimento do campo profissional e acadêmico das relações públicas no Brasil. In: KUNSCH, Margarida M. Krohling (org.). Relações públicas: história, teorias e estratégias nas organizações contemporâneas. São Paulo: Saraiva, 2009. p. 7-42.

NASSAR, Paulo; FURLANETTO, Mateus; FLYNN, Terry. Electrifying public relations: how a Canadian company created Brazil's first corporate public relations department. In: INTERNATIONAL HISTORY OF PUBLIC RELATIONS CONFERENCE, 6th, 2015. Annals... Public Relations Cluster, Faculty of Media \& Communication, Bournemouth University.

NASSAR, Paulo. A Aberje e a comunicação organizacional no Brasil. In: KUNSCH, Margarida M. Krohling (org.). Comunicação organizacional. Vol. I. Histórico, fundamentos e processos. São Paulo: Saraiva, 2009. p. 29-44.

. Alexander Mackenzie and the origin of Brazilian Public Relations. Publicado em16/05/2015. Disponível em: <http:// www.aberje.siteprofissional.com/acervo_colunas_ver.asp?ID_COLUNA=1514\&ID_COLUNISTA=28>. Acesso em: maio 2016.

Relações públicas na construção da responsabilidade histórica e no resgate da memória institucional das organizações. 3. ed. São Caetano do Sul, SP: Difusão; Rio de Janeiro: Senac Rio, 2012.

SIMÕES, Roberto Porto. Relações públicas: função política. 3. ed. São Paulo. Summus, 1995.

TORQUATO, Gaudêncio. Jornalismo empresarial: teoria e prática. 2. ed. São Paulo: Summus, 1987. Tratado de comunicação organizacional e política. São Paulo: Pioneira Thomson Learning, 2002.

Artigo recebido em 15.05.2016 e aprovado em 15.06.2016. 